\title{
Modeling of ammonothermal growth of nitrides
}

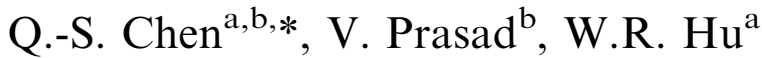 \\ ${ }^{\mathrm{a}}$ Institute of Mechanics, Chinese Academy of Sciences, 15 Bei Si Huan Xi Road, Beijing 100080, China \\ ${ }^{\mathrm{b}}$ Department of Mechanical Engineering, Florida International University, EC-2460, 10555 W Flagler St., Miami, FL 33174, USA
}

Received 29 November 2002; accepted 25 June 2003

Communicated by J.J. Derby

\begin{abstract}
Bulk single crystals of GaN and AlN can be grown from supercritical fluids using the ammonothermal method, which utilizes ammonia as fluid rather than water as in the hydrothermal process. In this process, a mineralizer such as amide, imide or nitride is used to attack a bulk nitride feedstock at temperatures from $200^{\circ} \mathrm{C}$ to $500^{\circ} \mathrm{C}$ and pressures from 1 to $4 \mathrm{kbar}$. Ammonothermal systems have been modeled here using fluid dynamics, thermodynamics and heat transfer models. The nutrient is considered as a porous media bed and the fluid flow is simulated using the Darcy-BrinkmanForchheimer model. The resulting governing equations are solved using the finite volume method. The effects of particle size on flow pattern and temperature distribution in an autoclave are analyzed.
\end{abstract}

(C) 2003 Elsevier B.V. All rights reserved.

Keywords: A1. Computer simulation; A2. Ammonothermal growth; B1. Nitrides

\section{Introduction}

$\mathrm{GaN}$ and related materials can be used to fabricate blue/green/UV emitters (LEDs and LDs), and high temperature, high power electronic devices [1]. Ideal substrates are needed for high quality III-nitride epitaxy, which is an essential step for the manufacture of light emitting semiconductor devices. SiC or Sapphire substrates have been typically used thus far, but sapphire has a large lattice mismatch with nitride-based

\footnotetext{
*Corresponding author. Institute of Mechanics, Chinese Academy of Sciences, 15 Bei Si Huan Xi Road, Beijing 100080, China. Tel.: 861062564199; fax: 861062615524.

E-mail addresses: qschen@imech.ac.cn (Q.-S. Chen), prasadv@fiu.edu (V. Prasad).
}

films and $\mathrm{SiC}$ substrates are expensive. AlN or $\mathrm{GaN}$ substrates are ideal to be lattice matched and isomorphic to nitride-based films.

Due to high melting temperatures and high dissociation pressures of III-nitride compounds, bulk nitride crystals are difficult to be grown. IIInitrides can decompose in metal and $\mathrm{N}_{2}$ or nitrogen atoms at high temperatures using melt or sublimation growth. To counteract the decomposition, a high nitrogen pressure or a high ammonia pressure is required. Porowski [2-4] used ultra-high-pressure method to synthesize gallium nitride single crystals in the form of hexagonal platelets with dimensions exceeding $1 \mathrm{~cm}$ from the solution in liquid gallium at nitrogen pressures of $12-20 \mathrm{kbar}$ and temperatures of $1400-1700^{\circ} \mathrm{C}$ [2-4]. Semiconductor $\mathrm{GaN}$ was obtained by 
introduction of $\mathrm{Mg}$ into the growth solution. The surface area of pressure-grown $\mathrm{GaN}$ single-crystalline platelets has been increased to about $100 \mathrm{~mm}^{2}$ recently by these authors [2-4].

Callahan et al. [5] synthesized and grew GaN by sublimation of ammonium chloride in a carrier gas, which passes over gallium at temperatures of approximately $900^{\circ} \mathrm{C}$ at near atmospheric pressure. GaN single crystal $c$-plane platelets up to $2 \times 2 \times 0.1 \mathrm{~mm}^{3}$ were obtained.

Purdy [6] synthesized both bulk cubic (zinc blende) and hexagonal GaN by ammonothermal reactions of gallium metal and compounds under acidic $\left(\mathrm{NH}_{4} \mathrm{Cl}, \mathrm{NH}_{4} \mathrm{Br}\right.$, or $\left.\mathrm{NH}_{4} \mathrm{I}\right)$ conditions. Gallium metal reacted slowly with supercritical $\mathrm{NH}_{3}$ in the presence of $\mathrm{NH}_{4} \mathrm{I}$, forming $\mathrm{GaN}$ as the only crystalline product at temperatures above $250^{\circ} \mathrm{C}$ and pressure of $10,000 \mathrm{psi}$. Ketchum and Kolis [7] grew single crystals of gallium nitride in supercritical ammonia at $400^{\circ} \mathrm{C}$ and $2.4 \mathrm{kbar}$. Hexagonal GaN crystal of $0.5 \times 0.2 \times 0.1 \mathrm{~mm}^{3}$ was obtained.

In the ammonothermal growth of nitrides ( GaN, AlN), the autoclave used is very similar to that in the hydrothermal growth of high quality oxides. Ammonia $\left(\mathrm{NH}_{3}\right)$ is used in the ammonothermal growth method instead of water as in the hydrothermal growth. Predetermined amounts of ammonia, mineralizers and $\mathrm{GaN}$ particles are loaded in the bottom of an autoclave, while seeds are hanged on a ladder made from $1.0 \mathrm{~mm}$ diameter Ag wire from the top (see Fig. 1a). A baffle made from $0.28 \mathrm{~mm} \mathrm{Ag}$ foil is used to divide the autoclave into two parts-upper and lower portions. One-half of the cylindrical autoclave used in Ref. [7] is shown in Fig. 1b, and the temperature contours are also shown. The part of the autoclave below the baffle is applied with a high temperature, $T_{\mathrm{H}}$, and the upper part of the autoclave, above the baffle, is applied with a low temperature, $T_{\mathrm{L}}$. The strap heaters on the sidewall of autoclave are controlled to obtain the required temperatures.

A temperature gradient is achieved on the sidewall of the autoclave, e.g., $300-250^{\circ} \mathrm{C}$ from the bottom to the top of the sidewall. A pressure of 2-4 kbar can be obtained with a $70-90 \% \mathrm{NH}_{3}$ fill. For mineralizer of $1-2 \mathrm{~N}$, the growth rate of $\mathrm{GaN}$

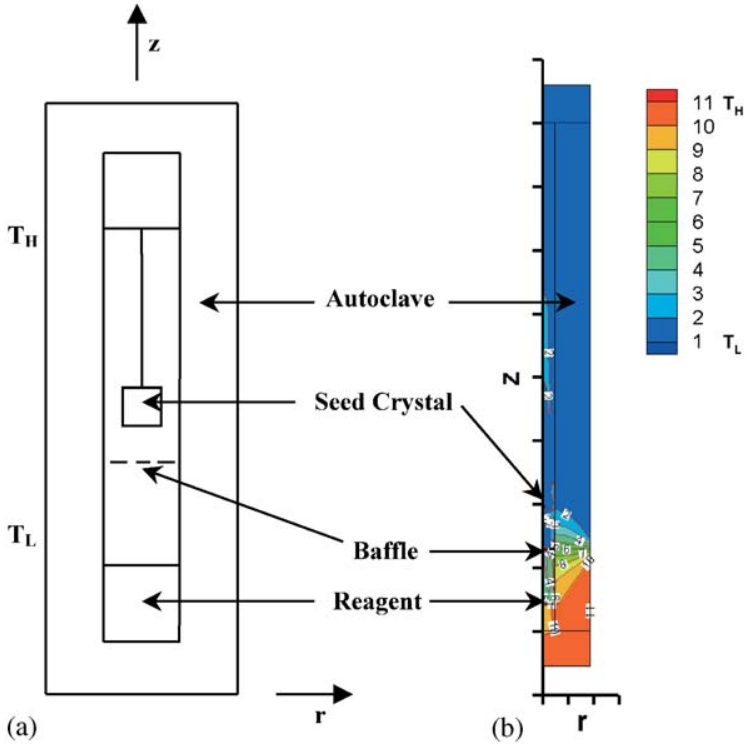

Fig. 1. (a) Schematic of an ammonothermal growth system and (b) one-half section of the autoclave, conditions are the same as in Fig. 2(b).

by ammonothermal method is only $1-50$ mils/day, about $1 / 10$ th of the growth rate of quartz by hydrothermal growth. GaN platelets of $1 \mathrm{~mm}$ in length can be produced by ammonothermal growth after a typical run of 5-30 days.

\section{Mathematical model}

After the ammonothermal system is pressurized, ammonia occupies most of the volume. Hence the upper portion can be considered as a fluid layer with the assumption of incompressible flow and the Boussinesq approximation [8,9]. The GaN particles in the bottom of the autoclave can be considered as a porous medium. In this case, the Darcy-Brinkman-Forchheimer model can be employed in the porous layer, while Navier-Stokes equations can be used in the fluid layer $[8,9]$. The non-dimensional parameters of the system are listed below:

$$
\begin{aligned}
& A r=H / R, \quad G r=g \beta R^{3}\left(T_{\mathrm{H}}-T_{\mathrm{L}}\right) / v^{2}, \\
& P r=K / R^{2}, \quad F s=b / R,
\end{aligned}
$$


where $A r, G r, P r, D a, F s$ denote aspect ratio, Grashof number, Prandtl number, Darcy number, and Forchheimer number, respectively. $H$ is the internal height of the autoclave, $R$ the internal radius of the autoclave, $g$ the acceleration due to gravity, $\beta$ the isobaric coefficient of expansion, $v$ the kinematic viscosity, $\alpha$ the thermal diffusivity, the permeability of porous matrix $K=$ $d_{\mathrm{p}}^{2} \varepsilon^{3} /\left[150(1-\varepsilon)^{2}\right]$ with $d_{\mathrm{p}}$ as the average diameter of the nutrient particles, and the Forchheimer coefficient $b=\left[1.75 /\left(\sqrt{150} \varepsilon^{1.5}\right)\right] K^{0.5}$. The porosity $\varepsilon=0$ in solid, $0<\varepsilon<1$ in porous layer and $\varepsilon=1$ in fluid layer, respectively.

The governing equations in the porous and fluid layers can be combined by defining a binary parameter $B$ as: $B=0$ in the fluid layer and $B=$ 1 in the porous layer, respectively. The combined governing equations in a cylindrical coordinate system are $[10,11]$ :

$$
\begin{aligned}
& \frac{\partial\left(\varepsilon \rho_{\mathrm{f}}\right)}{\partial t}+\nabla \cdot\left(\rho_{\mathrm{f}} \mathbf{u}\right)=0 \\
& \frac{\rho_{\mathrm{f}}}{\varepsilon} \frac{\partial \mathbf{u}}{\partial t}+\frac{\rho_{\mathrm{f}}}{\varepsilon}(\mathbf{u} \cdot \nabla) \frac{\mathbf{u}}{\varepsilon}=-\nabla p+\rho_{\mathrm{f}} g \mathbf{z} \\
& \quad+\nabla \cdot\left(\mu_{\mathrm{e}} \nabla \mathbf{u}\right)-B\left[\left(\frac{\mu_{\mathrm{f}}}{K}+\frac{\rho_{\mathrm{f}} b}{K}|\mathbf{u}| \mathbf{u}\right)\right]
\end{aligned}
$$

$\left(\rho c_{\mathrm{p}}\right)_{\mathrm{e}} \frac{\partial T}{\partial t}+\left(\rho c_{\mathrm{p}}\right)_{\mathrm{f}}[(\mathbf{u} \cdot \nabla) T]=\nabla \cdot\left(k_{\mathrm{e}} \nabla T\right)$,

where $\rho, \mu, k, c_{\mathrm{p}}$ denote density, dynamic viscosity, thermal conductivity, and specific heat, respectively. $\mathbf{z}$ is the unit vector in the $z$ direction. Subscript f, e denote fluid and effective, respectively.

A temperature profile is set on the sidewall of the autoclave, $T=T_{\mathrm{H}}, z<H_{\mathrm{B}}-0.5 \delta_{T} ; T=T_{\mathrm{H}}-$ $\left(T_{\mathrm{H}}-T_{\mathrm{L}}\right) / \delta_{T}\left(z-H_{\mathrm{B}}+0.5 \delta_{T}\right) ; T=T_{\mathrm{L}}, z>H_{\mathrm{B}}+$ $0.5 \delta_{T}$, where $H_{\mathrm{B}}$ is the height of the baffle, and $\delta_{T}$ is the height of the wall where the temperature changes from $T_{\mathrm{H}}$ to $T_{\mathrm{L}}$. The top and bottom of the autoclave are considered adiabatic. The temperature distribution is considered axisymmetric, $\partial T / \partial r=0$, at $r=0$. The following scales are used to non-dimensionalize the governing equations: length $R$; velocity, $v / R$; time, $R^{2} / v$; pressure, $\rho v^{2} / R^{2}$; and temperature, $T_{\mathrm{H}}-T_{\mathrm{L}}$. The nondimensional coordinates and velocity components are $\left(r^{\prime}, z^{\prime}\right)=(r / R, z / R),\left(u^{\prime}, w^{\prime}\right)=(u / R, w / R)$, re- spectively. The primes are omitted in the following analysis. Grid used here is $302 \times 77$, and time step is $\mathrm{d} t=5 \times 10^{-6}$. Different grid sizes, such as $257 \times 67$ and $302 \times 77$, have been used to test the grid independence, more details on grid independence test can be found in Ref. [10]. More details on numerical scheme can be found in Ref. [12].

\section{Results}

The critical properties of ammonia are $T_{\mathrm{c}}=405.5 \mathrm{~K}$, and $P_{\mathrm{c}}=11,280 \mathrm{kPa}$. The reduced pressure and reduced temperature at $2 \mathrm{kbar}$ and $250^{\circ} \mathrm{C} \quad$ are $\quad P_{\mathrm{r}}=2000 / 112.8=17.7, \quad T_{\mathrm{r}}=$ $523 / 406=1.3$. For $P_{\mathrm{r}}=10$, and $T_{\mathrm{r}}=1.3$, the viscosity and conductivity of ammonia are $\mu / \mu_{1}=$ $4.3, k / k_{1}=5.0$, where $\mu_{1}$ and $k_{1}$ are the dynamic viscosity, and thermal conductivity at $250^{\circ} \mathrm{C}$ and atmospheric pressure [13].

We consider a case in which the autoclave has an internal diameter of $0.932 \mathrm{~cm}$, external diameter of $3.5 \mathrm{~cm}$, internal height of $18.4 \mathrm{~cm}$ and external height of $20.3 \mathrm{~cm}$ (Tem-Press MRA 138R with a volume of $12.5 \mathrm{ml}$ ) [7]. The thicknesses of the sidewall and bottom of the autoclave are $1.28 \mathrm{~cm}$. The charge height is $1 \mathrm{~cm}$, and the charge particle size is $0.6 \mathrm{~mm}$. The gap between the baffle and charge bed is $2 \mathrm{~cm}, T_{\mathrm{H}}-T_{\mathrm{L}}$ applied on the sidewall is $50 \mathrm{~K}$, and $\delta_{T}=1 \mathrm{~cm}$. The baffle is made of $0.28 \mathrm{~mm} \mathrm{Ag}$ foil. The aspect ratio, Grashof number, Prandtl number, Darcy number and Forchheimer number are, $A r=40, G r=$ $4.46 \times 10^{6}, \quad \operatorname{Pr}=0.73, \quad D a=2.2 \times 10^{-5}, \quad F s=$ $2.6 \times 10^{-3}$, respectively.

The flow pattern is shown in Fig. 2a. The flow in the porous layer is much weaker than that in the fluid layer. The modified Grashof number can be used to measure the flow strength in the porous charge, $G r^{*}=G r D a$. In this case, the modified Grashof number is $G r^{*}=98.2$. The fluid flow cannot penetrate the porous layer, and the heat and mass transfer in the porous layer is mainly by conduction and diffusion, respectively. The constraints for the ammonothermal growth include dissolving of charge, transfer of nutrient from the charge to seed, and growth of crystals. The mass transfers between the porous layer and the fluid 

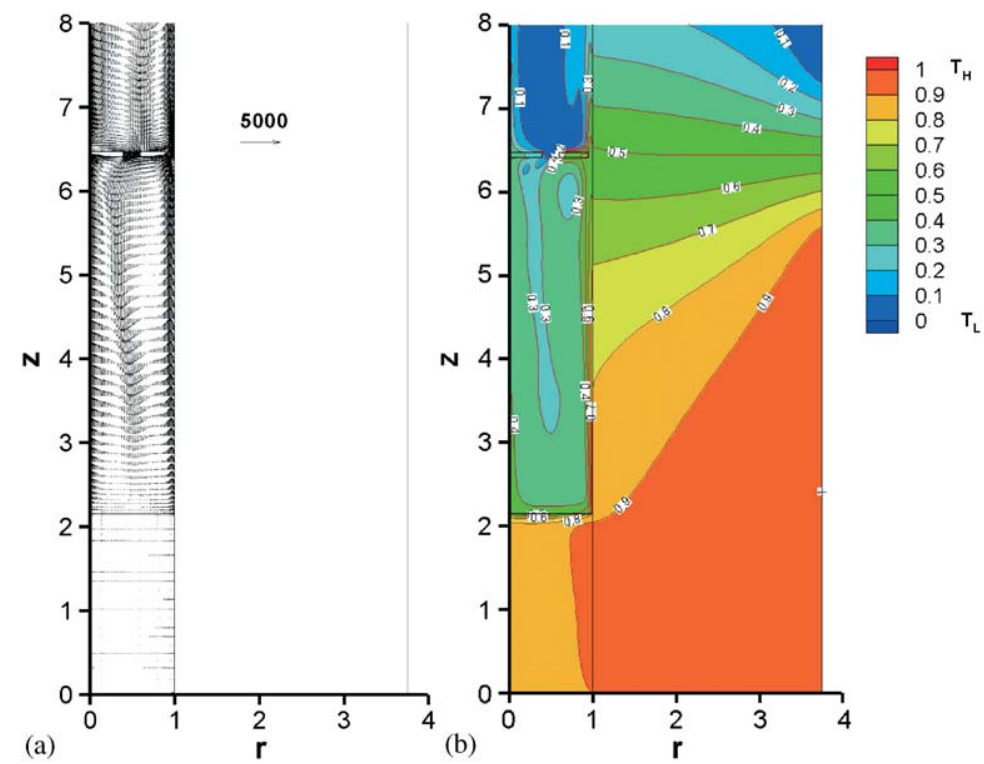

Fig. 2. (a) Fluid flow in the autoclave with internal diameter of $0.932 \mathrm{~cm}$, internal height of $18.4 \mathrm{~cm}$, particle size of $0.6 \mathrm{~mm}$, and $\Delta T=50 \mathrm{~K}$, and (b) temperature distribution in the autoclave.

layer is important for the successful growth. The flow strength in the fluid layer depends on Grashof number, which is proportional to the temperature difference on the sidewall and the cubic of the internal diameter of the autoclave. It is obvious that the flow strength will be greatly increased by increasing the internal diameter of the autoclave. On the other hand, the flow in the porous layer depends on Grashof number and Darcy number, which is proportional to the square of the diameter of particles. For a fixed system, the flow strength in the porous layer can be increased by increasing the size of particles.

The temperature distribution is shown in Fig. $2 \mathrm{~b}$. The temperatures in the porous charge are almost the same as the high temperature, $T_{\mathrm{H}}$, applied on the lower part of the sidewall of the autoclave. Large temperature gradients appear near the fluid/charge interface. The aspect ratio in this case is about 40 , the temperatures at $z>20$ within the autoclave are almost the same as the low temperature, $T_{\mathrm{L}}$, applied on the upper part of the sidewall of the autoclave.

Since the aspect ratio of the inner chamber of the autoclave is 40 , it is difficult to show the whole picture of flow field inside the autoclave. We have therefore plotted the flow field around the baffle in Fig. 3a. We assume that the baffle has a central opening of $20 \%$ in the cross-sectional area of the autoclave, and a gap between the baffle and autoclave of $10 \%$ in the cross-sectional area. There are two flow cells rotating in different directions under the baffle. The flow goes up along the sidewall driven by the buoyancy, which is caused by the high temperature applied on the lower part of the sidewall. Some flow penetrates through the gap between the baffle and the sidewall of the autoclave, and some flow goes inward along the baffle and then downward near the central opening of the baffle.

The vertical velocity profiles with respect to radius at different heights, $z=1,5$ and 6.45 , within the autoclave are plotted in Fig. 3b. The vertical velocity is very small at $z=1$ in the porous layer meaning the flow is weak in the charge. The flow structure between the baffle and charge is complex as depicted by the curve at $z=5$. The flow goes up through the gap between the baffle and sidewall as shown by the curve at $z=6.45$. The flow is highly three-dimensional as the Grashof number is high. For three-dimensional calculations in a hydrothermal system, one can refer to Ref. [11]. 
Another case is considered in which the charge particle size is $3 \mathrm{~mm}$. In this case, the Darcy number in the charge is 25 times as much as in the previous case. Figs. $4 \mathrm{a}$ and $\mathrm{b}$ show the flow pattern and temperature distribution in the autoclave, respectively. The modified Grashof number is $G r^{*}=2455$, and significant convective effects are seen occurring in the charge (Fig. 4a). As can be seen from Fig. 4b, the temperature distribution in the charge is in convection mode, and large temperature gradients appear near the interface between the charge and the sidewall of the autoclave. It is obvious that the particle size is an important factor to be considered for the success-
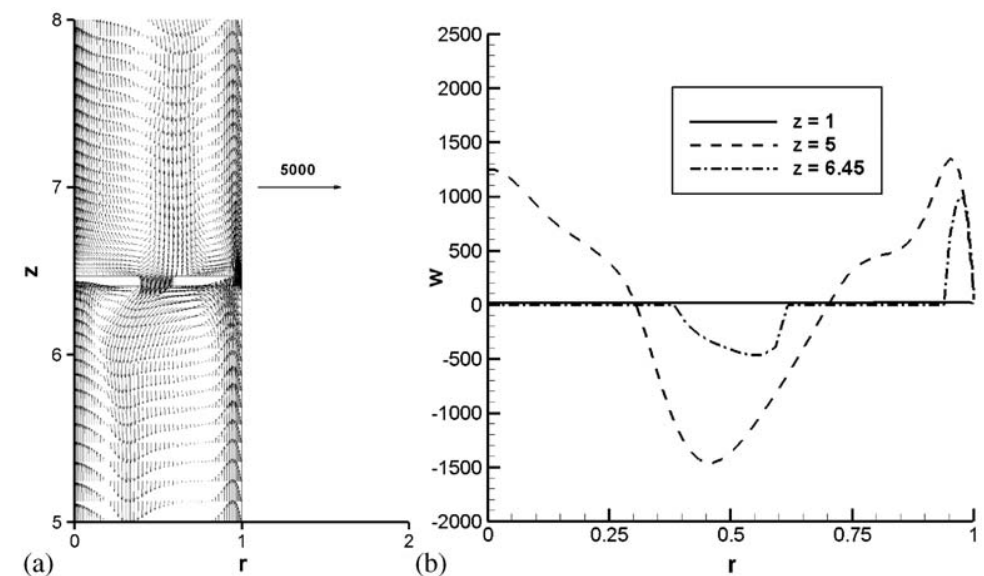

Fig. 3. (a) Enlarged picture of Fig. 2a, and (b) velocity profiles along the radial direction at different heights within the autoclave.
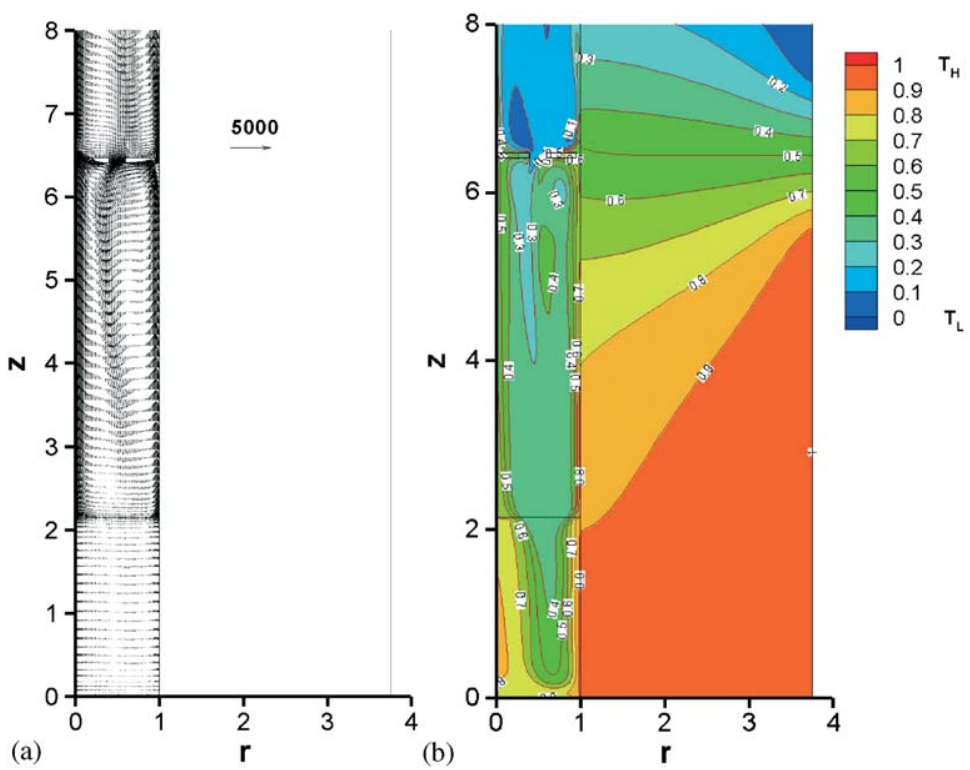

Fig. 4. (a) Fluid flow and (b) temperature distribution in a growth system with particle size of $3 \mathrm{~mm}$ and $\Delta T=50 \mathrm{~K}$. The autoclave has an internal diameter of $0.932 \mathrm{~cm}$ and internal height of $18.4 \mathrm{~cm}$. 

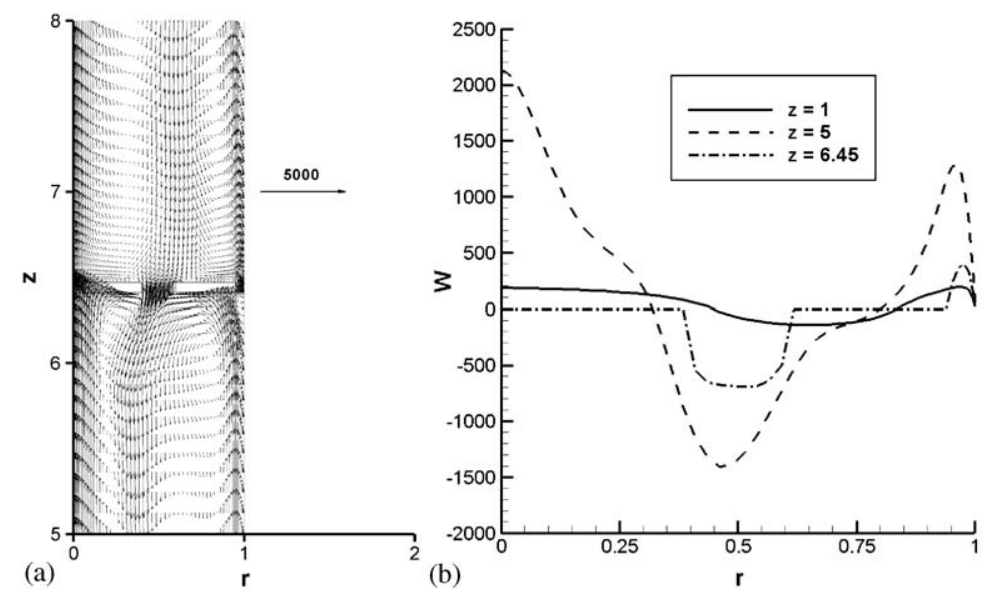

Fig. 5. (a) Enlarged picture of Fig. 4a, (b) velocity profiles along the radial direction at different heights within the autoclave.

ful growth of GaN by ammonothermal method, especially when the ammonothermal growth system is upscaled.

Similarly we plot the flow field around the baffle in Fig. 5a. There are again two flow cells below the baffle. The flow structure above the baffle is complex and oscillating. The vertical velocity profiles are plotted in Fig. 5b. The velocity is large at $z=1$ in the porous layer as compared to Fig. $3 \mathrm{~b}$, since the modified Grashof number is 25 times as much as in the previous case. The flow goes up through the gap between the baffle and the sidewall, and the flow is oscillating in the central hole.

\section{Discussions}

An ammonothermal growth system is considered here in which the autoclave used has an internal diameter of $0.932 \mathrm{~cm}$ and internal height of $18.4 \mathrm{~cm}$. For the case of particle size of $0.6 \mathrm{~mm}$, the flow in the charge is very weak, and the temperature distribution in the charge is in conduction mode. This may constrain mass transfer in the charge and affect the growth of GaN. The flow strength can be increased by increasing the size of the particles, etc. from 0.6 to $3 \mathrm{~mm}$. The temperature distribution in the charge is in convection mode with the particle size of $3 \mathrm{~mm}$. The flow is highly three dimensional in the fluid layer since the Grashof number is high Two-dimensional calculations are suitable for parameter studies.

\section{Acknowledgements}

The authors would like to thank J.W. Kolis of Clemson University for helpful discussions.

\section{References}

[1] S.J. Pearton, R.J. Shul, F. Ren, MRS Internet J. Nitride Semicond. Res. 5 (2000) 11.

[2] I. Grzegory, M. Bockowski, B. Lucznik, S. Krukowski, M. Wroblewski, S. Porowski, MRS Internet J. Nitride Semicond. Res. 1, Article 20 (1996).

[3] S. Porowski, J. Crystal Growth 189/190 (1998) 153.

[4] S. Porowski, MRS Internet J. Nitride Semicond. Res. 4S1 (1999) G1.3.

[5] M. Callahan, M. Harris, M. Suscavage, D. Bliss, J. Bailey, MRS Internet J. Nitride Semicond. Res. 4 (1999) 10.

[6] A.P. Purdy, Chem. Mater. 11 (1999) 1648.

[7] D.R. Ketchum, J.W. Kolis, J. Crystal Growth 222 (2001) 431.

[8] V. Prasad, Convective flow interaction and heat transfer between fluid and porous layers, in: S. Kakaç, et al., (Eds.), Convective Heat and Mass Transfer in Porous Media, Kluwer, Netherlands, 1991, p. 563.

[9] Q.S. Chen, V. Prasad, A. Chatterjee, J. Larkin, J. Crystal Growth 198/199 (1999) 710. 
[10] Q.-S. Chen, V. Prasad, A. Chatterjee, J. Heat Transfer 121 (1999) 1049.

[11] Q.-S. Chen, H. Zhang, V. Prasad, C.M. Balkas, N.K. Yushin, J. Heat Transfer 123 (2001) 1098.

[12] Q.-S. Chen, V. Prasad, Modeling of ammonothermal growth of nitrides and applications, In: K. Byrappa, H.
Klappaer, T. Ohachi, R. Fornari (Eds.), International School on Crystal Growth of Technologically Important Electronic Materials, Allied Publishers Pvt Ltd, New Delhi, ISBN 81-7764-375-4, p. 61.

[13] A.J. Chapman, Heat Transfer, Macmillan Publishing Company, New York, 1984. 